\title{
IMAGÉTICA GROTESCA
}

Prof. Dr. Antonio Vargas

PPGAV-CEART/UDESC

\section{Resumo}

O texto apresenta uma pesquisa em poéticas desenvolvida através da linguagem pictórica tendo como base a construção de imagens em ambiente digital. Apoiada nos conceitos de apropriação, grotesco e ukiyo-e a pesquisa tem como recorte temático a presença de imagens de sexo explícito e violência na vida cultural contemporânea e, visa tanto a reflexão sobre a atualidade da estética grotesca como o desenvolvimento de uma fatura pictórica capaz de atualizar o conceito de pintura de gênero.

\section{Abstract}

The article introduces a research in developed poetic through the pictorial language having as base the images preparation in digital environment. Supported in the appropriation concepts, grotesque and ukiyo-e the research has as thematic cutting the presence of images with explicit sex and violence in the contemporary cultural life and, has as goal so much the reflection on the actuality of the grotesque aesthetics as the development in a way doing able to pictorial update the gender painting concept.

\section{Palavras-chaves}
- Digital art
- Grotesco
- Ukiyo-e
- Digital art
- Grotesque
- Ukiyo-e

Key words

\section{Atualidade estética}

A incorporação de obras de arte - na forma de cópia - para criação de obras artísticas novas é um fenômeno antigo, porém as digitalizações das imagens na contemporaneidade e sua veiculação através da internet ampliaram potencialmente as possibilidades de apropriações visuais. A prática, chamada de 
citacionismo (CHIARELLI in BASBAUM, 2001), é uma característica recorrente na arte contemporânea e estimula discussões sobre direitos de autor, originalidade, cópia e transgressão pois, concomitantemente, as integrações e fusões das mídias através da digitalização das imagens e dos sons (televisão, internet, telefonia e rádio) modificam as formas de recepção pelo público e redimensionam seu conceito de arte.

Nos projetos de pesquisa Grotesco ${ }^{1}$ e Imagética Grotesca a relação entre apropriação artística e vida contemporânea esta correlacionada e mediada ao conceito de grotesco e a utilização de fragmentos de Ukiyo-e (s) do Período Edo como estratégia de criação.

A relevância do grotesco na arte é bastante consolidada (KAISER, 19860). A imagem grotesca possui um poder de atração, de sedução e ao mesmo tempo de repulsa, de desconforto e sua presença na arte contemporânea pode ser claramente percebida nas obras de artistas como os irmãos Chapmann, Gilbert \& George, Serrano, C. Ofili, J. Koons, Bettina Rheims, Paula Rego, J. Currin, R. Mapplethorpe, Louise Bourgeois, Bruce Conner, Inka Essenhigh, Tom Friedman, Ellen Gallagher, Robert Gober, Douglas Gordon, Paul McCarthy, Sigmar Polke, Susan Rothenberg, Jenny Saville, Cindy Sherman, Kara Walker para citar apenas alguns poucos.

Nas imagens produzidas para o projeto Imagética Grotesca o processo de manipulação e construção da imagem digital é de apropriação e manipulação de imagens digitais captadas via internet com vistas a construção de uma nova visualidade que tem por parâmetro o Ukiyo-ê. Uma vez finalizada a imagem esta é impressa sobre tela servindo como referência para a confecção de pinturas a óleo que preservam justamente as características de uma imagem construída no ambiente digital. A estratégia de preservar a referência do ambiente digital como fonte de origem da matriz pintada esta em sintonia com a produção pictórica contemporânea como evidenciam algumas obras recentes de Jeff Koons ou Simeón Saiz Ruiz, por exemplo. Trata-se de um procedimento que reatualiza esteticamente um princípio do hiperrealismo, a saber, a construção de uma ${ }^{1}$ Projeto contemplado com financiamento da FAPESC. 
imagem pictórica que desvela a sua referência ao preservar algumas das características da fonte. Nem nossa pesquisa, no uso de imagens digitais impressas como base para a pintura, preserva-se o desfocado ou as distorções decorrentes das manipulações de pixels bem como determinados "aspectos" típicos de efeitos de manipulação usuais em softwares de tratamento de imagens. O uso da impressão sobre tela como procedimento pré-pictórico justifica-se por questões intrínsecas ao tipo de fatura desenvolvida pois ao contrário dos procedimentos pictóricos do hiperrealismo em nosso projeto não ocultamos a marca da pincelada, da espátula ou da gestualidade.

A utilização de projeção sobre a tela como guia para o procedimento pictórico gera uma imagem na qual a cor é idêntica da imagem digital. $\mathrm{Na}$ impressão sobre a tela, devido a base e ao tipo de tinta empregada na impressão, a imagem resultante se assemelha a primeira camada magra de tinta, ou seja, apenas uma vaga noção de cor permanece ao passo que a estrutura formal da imagem é preservada, mantendo-se as distorções de pixels produzidas durante a manipulação em ambiente digital. O resultado é a confecção de uma "guia" que permite ao pintor maior liberdade na manipulação das cores uma vez que a pintura passa a ser construída a partir da interação da cor pigmento e não da cor luz, estimulando ou propiciando ambiente confortável para utilização de recursos plásticos como espatulados e pastosidades próprias da tinta óleo.

Não se trata, portanto, de copiar a imagem digital ou colorir uma imagem passada para a tela e sim de elaborar uma "fatura pictórica" que somente pode existir como tal pela pré-existência de uma experiência de percepção e confecção de uma imagem digital.

\section{Problematizando a pintura}

Se na primeira parte desta investigação o processo de confecção da imagem findava com a impressão das imagens digitais, na segunda etapa ao adotarmos a utilização da pintura como recurso de linguagem para a construção imagética nos deparamos com a necessidade de problematizar o conceito de 
pintura. Dado que o tratamento das temáticas sobre sexo e violência se faz mediante imagens fotográficas da vida contemporânea, entendemos que 0 conceito de Pintura de Gênero é o mais adequado para a problematizar.

$\mathrm{Na}$ cultura ocidental, a vida cotidiana somente passou a ser uma temática digna de ser representada pela arte oficial após o fim da Idade Média com o surgimento do naturalismo Gótico - através das iluminuras e, especificamente, dos Livros das Horas - com a representação de hábitos e costumes cotidianos, principalmente cortesãos (cenas de caça, passeios no campo). Importante ter presente que nas iluminuras encontramos um grande número de representações grotescas.

Também foram objetos de representação cenas populares como os trabalhos agrícolas, que tinham uma importância alegóricas dentro do cristianismo. Mas é com o ressurgimento da classe média - que logo se tornaria o personagem mais freqüente neste tipo de composição pictórica - que as temáticas do cotidiano ganham independência.

Cabe lembrar que, desde o século XV como parte de um processo mais amplo de secularização da cultura, a importância da burguesia no cenário social geral foi tão gradual quanto sua aparição nas cenas representadas.

A partir do século XVII a opulência da temática cotidiana dominou o quadro e a cena religiosa foi suprimida, dando origem a dois gêneros que marcaram a arte dos séculos seguintes: a Natureza-Morta e a Pintura de Gênero, destacando personagens populares, ou pelo posicionamento frente ao cenário ou/e pelas ações que realizavam, conferindo-Ihes uma relativa sensualidade. No início esta foi vista como um subgênero, e suas obras como obras "sem tema" - de valor inferior dentro do mercado de arte.

Este gênero desenvolveu-se mais amplamente na parte norte dos Países Baixos (atual Holanda), onde não havia uma corte (uma vez que a região era organizada em províncias), nem um clero sediado (já que eles adotaram o recém surgido protestantismo). Sua origem nessa região está associada às ricas cenas pintadas por Bruegel, em suas cenas de camponeses em atividades cotidianas, que se tornaram extremamente influentes entre os artistas da época. A Holanda 
de então, habitada por uma próspera população burguesa, vinha refinando seus modos de vida, seu gosto e se tornando consumidora fiel de arte e devido a dimensão de suas casas, menores que os suntuosos palácios da nobreza, adotaram os pequenos para suas pinturas de temáticas cotidianas .

Uma característica bastante marcante do gênero é o extremo naturalismo que, muitas vezes, chega ao realismo burguês. Ele está completamente voltado para o homem e para a natureza, assim como para as cenas e motivos que faziam parte da existência diária e pessoal: os aposentos das casas, o pátio, a cidade, a paisagem local, a fachada da rua e, de forma bastante inovadora e singular, a mulher em suas atividades domésticas.

É importante observar que, no geral deste gênero, as pessoas são registradas por suas atividades profissionais ou classe social, diferente dos retratos, em que eram retratados como indivíduos (por exemplo, exibindo objetos particulares, medalhas conquistadas e brasões de família). Daí a recorrência de cenas da vida cotidiana, de trabalho e de festas, além das atividades domésticas.

Por sua vez, como já destacamos em artigo anterior, o termo Ukiyo-e quer dizer imagens do mundo flutuante e com isso define o registro da vida em seu caráter efêmero ou transitório. Se tomamos como referência as imagens produzidas por Utamaro, Hokusai, Hirosada, Kunisada e Toyokuni apenas para citar os nomes mais conhecidos de criadores de Ukiyo-e(s), podemos observar uma diferença substancial no foco do registro da vida cotidiana uma vez que são soldados (samurais), cortesãs (gueixas) e atores que predominam. Devido a uma relativa paz social do período Edo os Ukiyo-e(s) registram imagens de afazeres e desfrutes da vida cotidiana, não raro com picantes imagens de sexo explícito. De fato, como bem demonstra Afonso Medeiros (2005) o universo imagético do Ukiyo-e pode ser entendido sob o conceito de crônica, mas pensamos também que, não seria de todo equivocado entendê-lo como uma variante não ocidental da pintura de gênero. Embora usualmente a palavra Ukiyo-e seja associada as gravuras, o termo em si é genérico e se refere a todo um conjunto de imagens que abordam o "mundo flutuante", incluindo pinturas. E mesmo as gravuras que em seu processo eram freqüentemente alteradas e reimpressas podem ser 
entendidas como pinturas ( HASHIMOTO 2002: pp325)

Em nossa investigação, ao juntarmos a referência do Ukiyo-e com a linguagem da pintura a óleo e o uso de imagens de sexo e violência praticadas por atores sociais contemporâneos extraídas via internet, buscamos problematizar o conceito de pintura de gênero de forma a pensar suas possibilidades atuais como linguagem pictórica contemporânea. Com isto sobrepomos o conceito de criação partilhada próprio do Ukiyo-e ao de apropriação digital e citacionismo comuns à arte contemporânea bem como o registro de práticas cotidianas de atividades profissionais típicos da pintura de gênero ao registro de práticas comportamentais de soldados, policiais, militantes políticos e prostitutas contemporâneos fazendo com isto ademais outro paralelo ao Ukiyo-e. A junção de diferentes referências culturais habitando o mesmo espaço pictórico bem como a manutenção de signos majoritariamente incompreendidos na cultura ocidental como é o caso da presença dos selos de assinatura dos Ukiyo-e(s) de referência, são elementos intencionais presentes que pretendem também contribuir para problematizar 0 conceito em cada tela.

O resultado (http://www.casthalia.com.br/antonio_vargas.htm) é um conjunto de imagens que registram práticas comportamentais típicas da vida contemporânea, em temáticas demarcadas e freqüentes nas mídias atuais, realizadas por atores sociais bastante específicos e elaboradas mediante um processo de sobreposição conceitual que recupera e rediscute estratégias pictóricas.

\section{REFERENCIAS BIBLIOGRAFIA.}

BASBAUM, R. (Org) Arte contemporânea Brasileira. Ed. Marca dÁgua . RJ .2001 HASHIMOTO, Madalena. Pintura e escritura do mundo Flutuante: Hishikawa Moronobu e ukiyo-e Ilhara Saikaku e ukiyo-zôshi. Ed. Hedra. São Paulo, 2002.

KAYSER, Wolfgang. O grotesco. São Paulo: Perspectiva, 1986. 
MEDEIROS, Afonso. Crônica visual ou a modernidade do prosaico:notas sobre a gravura japonesa. In MARTINS, Alice Fátima e outros.Cultura visual e desafios da pesquisa em artes. 14 encontro ANPAP Vol. 1, Ed. UFG. Goiania, 2005.

MUNIZ SODRÉ. et PAIVA,Raquel. O Império do grotesco. Rio de Janeiro: MAUAD,2002

OLIVARES, Rosa. Em cuerpo y alma. In Lapiz, Revista Internacional de Arte. N.139/140, Enero/Febrero. Madrid, 1998

Web-sites

http://www.casthalia.com.br/a_mansao/guia_educador.htm

Antonio Vargas é Doutor em Artes pela Universidad Complutense de Madrid (1992), Pós-Doutorado pela Universitat de Barcelona (1996), Professor Adjunto do Centro de Artes da UDESC, atua no Mestrado em Teatro e no Mestrado de Artes Visuais da UDESC. Artista Visual com exposições no Brasil e exterior.

Endereço: Rua Agostinha Maria da Conceição, 198. Florianópolis, 88061-450 SC Contatos: 48- 3232 3593/ 48- 99613644

E-mail: antoniotot@yahoo.com.br 